
\title{
25 Research Square \\ Critical Time Intervention to Facilitate Exiting Sex Work: Lessons Learned From a Fidelity Assessment
}

\section{Melissa Perri}

University of Toronto Dalla Lana School of Public Health https://orcid.org/0000-0002-8279-0442

Martine Shareck ( $\square$ Martine.Shareck@USherbrooke.ca )

Département des sciences de la santé communautaire, Université de Sherbrooke https://orcid.org/0000-0001-9162-3374

\section{Pearl Buhariwala}

St Michael's Hospital

\section{Maha Hassan}

St Michael's Hospital

\section{Patricia O'Campo}

St Michael's Hospital

\section{Research}

Keywords: Critical Time Intervention, Implementation, Process evaluation, Fidelity Assessment, Sex Work

Posted Date: August 30th, 2021

DOl: https://doi.org/10.21203/rs.3.rs-845804/v1

License: (c) (i) This work is licensed under a Creative Commons Attribution 4.0 International License.

Read Full License 


\section{Abstract}

\section{Introduction}

Individuals who engage with sex work face barriers to maintaining overall health and well-being such as criminalization, stigmatization, and violence. An emerging approach to facilitating exiting sex work for individuals is through programs applying the Critical Time Intervention (CTI) model. CTI represents a time-limited practice that supports vulnerable individuals during periods of transition. The objectives of this study were to apply an existing CTI fidelity assessment to the sex work exiting program Exit Doors Here (EDH) to (1) report on the program's fidelity and (2) discuss the effectiveness of CTI for supporting these groups.

\section{Methods}

To determine the applicability to the EDH of an existing fidelity assessment tool, we consulted with program staff through in person meetings. Staff highlighted areas for adaptation. We adapted the tool based on this feedback and used it to assess program fidelity by analyzing data from 8 participants' CTI notes. Fidelity ratings were computed and interpreted according to established guidelines.

\section{Results}

Consultations with program staff resulted in adaptations to seven items out of the 12 comprising the fidelity assessment tool. The majority of adaptations surrounded the time-limited nature of CTI and unique needs of the program participants. In regards to the fidelity assessment using the adapted tool, half of the items were ideally implemented, one was well implemented, one was fairly implemented and two were respectively found to be poorly implemented and not implemented at all.

\section{Conclusions}

Difficulties in implementing selected program components with high fidelity can be attributed to specificities of the target population and to contextual factors, which are hard to control from a staff and program standpoint. This assessment reiterates the importance of considering such factors when developing and implementing programs aimed at improving the health and well-being of marginalized women such as those who engage in sex work.

\section{Contributions To The Literature}

- Fidelity assessments of Critical Time Intervention based programs have demonstrated they are effective in assisting vulnerable populations during key transition periods. Despite this, limited research exists that speaks to the appropriateness of Critical Time Intervention for women who attempt to exit sex work.

- We found that many components of the Critical Time Intervention model (e.g., time limited nature) were not appropriate for providing care to women who engage with sex work due to their transient 
nature and intersecting marginalizing circumstances.

- Considering population specificities and contextual factors is key to providing effective health and social care to these groups.

- These findings contribute to existing gaps in the implementation science literature and program development which aims to assist women exit sex work. Future research is needed to determine what programs are effective for these groups.

\section{Background}

\section{Program Fidelity}

Assessing program fidelity is a key component of a process or formative program evaluations which helps determine whether a program adheres to the theory of change and has been implemented as initially planned (1). However, program implementation evaluations are rare, in part because it is assumed that staff training and protocols will ensure programs are implemented as designed. Fidelity assessments prevent the occurrence of Type III error in evaluations (e.g., "measuring something that does not exist")(2). Breitenstein et al.(3) define implementation fidelity as "the degree to which an intervention is delivered as intended and is critical to successful translation of evidence-based interventions into practice". Evaluating program fidelity also provides the opportunity to determine if any unintended activities or strategies, both positive and negative, have been inadvertently introduced (2). Conducting such assessments allows developers to determine areas of improvement for current and future program implementation (4). Quantitative fidelity assessment requires the creation of a program specific fidelity tool that captures key components needed for program success as well as the level of implementation of those components.

\section{Sex work in Canada}

The prevalence and subsequent criminalization of sex work has been prominent across Canada for years (5). In Canada, there were over 16,000 reports of sex work incidents from 2009 to 2014 (6). Human trafficking has also become a growing concern across Canada, with $90 \%$ of its victims being female and 93\% Canadian citizens (7). Although involving both sexes, reports from Vancouver, Canada found that approximately $80 \%$ of sex workers identified as female - which present unique gendered challenges (8, 9). Often, women enter into the area of sex work due to experiences of poverty, challenges in attaining employment or as a result of pressure from an existing or former partner $(10,11)$. When engaging in sex work, women commonly experience sexual and physical abuse, have heightened mental health illnesses and engage in substance use $(12,13)$. The criminalization of sex work augments pre-existing vulnerabilities faced by these target populations (14). Economic and criminal consequences such as fines or prison convictions push individuals deeper into health and social inequities (15).

These commonly experienced consequences significantly hamper women involved in sex work or women who are trafficked, to exit sex work and find suitable economic alternatives to create stable lives. 
Similarly, factors such as poverty, health challenges, romantic relationships, and limited education and employment opportunities contribute to these challenges (16). Programs designed to assist women who wish to exit sex work include diversion programs, residential treatment centres, or case management (17). These vary in structure and include services such as psychoeducational programs, linking individuals to community-based health and social services, or facilitating discussion with outreach workers $(13,18,19)$. Despite being commonly implemented, too few of these programs are demonstrated to be effective in assisting women who engage in sex work to obtain stable housing, health care or employment that is non sex work related, and ultimately exit sex work (20).

One emerging approach to supporting the transition from sex work to alternative means of employment involves applying Critical Time Intervention (CTI) (21). CTI "is a time-limited evidence-based practice that mobilizes support for society's most vulnerable individuals during periods of transition"(22). Thus, keeping participants focused, supported, and on track during a period of transition, CTI, a nine-month program, promotes continuity of care while facilitating integration into a community network of services to support ongoing transition and stabilization after completing the program. CTI originated to facilitate the transition of individuals experiencing homelessness to housing but has recently been used in a variety of transitions for individuals facing multiple social challenges including the transition after release from prison (23), facilitating reduced use of emergency room visits (24), assisting women affected by domestic violence transitioning out of shelters (25), and stabilizing individuals who have hoarding disorders at risk of eviction $(23-26,29)$.

\section{CTI among female sex workers: The Exit Doors Here program}

CTI has also recently informed sex work exiting programs, such as the Exit Doors Here (EDH) program, which the present paper focuses on. EDH assists women who express an interest in exiting sex work through addressing employment and other related issues such as housing, addiction, or poor health. Core to $\mathrm{CTI}$ are participants' identified goals and strategies pertaining to selected focus areas including mental health, health and wellness, employment, community skills, parenting, relationships with friends and family and housing. Goals are aimed to be achieved over three phases each lasting three months: Transition to the Community, Try Out, and Transfer of Care (22). CTI is designed to promote community integration by providing clients with a range of services and support systems to assist in their transition. Individuals begin the program in a pre-CTI phase, where they collaborate with case workers to develop relationships and discuss contextual factors that are relevant to successful transition $(27,28)$. In the Transition phase, staff begin providing support and assisting individuals navigate health and social services (22). For the Try-Out phase, focus is placed on strengthening support networks for participants (22). The final phase, Transfer of Care, represents the termination of CTI care and the full implementation of community supports (22). The underlying rationale for CTI is the idea that developing rapport with community agencies is essential to assist individuals' progress out of high risk lifestyles (27). Not only is the program complex, with staff and clients having to work on several challenging issues simultaneously, but the model also aims to make rapid progress within fixed time periods. 
Given the complexity and special nature of CTI (e.g., its focus on time-limited practices), specific training and adaptations were needed in order to apply it to the EDH program. EDH case managers received one week of intensive training by a CTI trainer from the Centre for Urban Community Services. This was done as a way to ensure that all case managers understood and could apply the key components of the CTI model. In this context, assessing program fidelity might help program staff identify where improvements can be made to increase adherence to, or adapt, the core model. A few of the aforementioned programs focused on implementation evaluation and we add to that growing literature about challenges with adhering to program fidelity $(23,29)$. CTI exists for a number of populations and issues, and since different programs and populations might harbor specificities which may influence key program components, existing fidelity tools must first be adapted to fit the population and types of transition they are aiming for.

\section{Objectives}

The objectives of this study were to: 1) apply an existing CTI fidelity assessment tool to a program aimed at assisting women exit sex work; 2 ) report on program fidelity for the early years of the program; and 3 ) highlight specificities of the context and population which might need to be considered in other programs supporting women transition out of sex work.

\section{Methods}

\section{Fidelity Scale Adaptation}

The fidelity tool we implemented was adapted by de Vet and colleagues (2017) (30) for a CTI program for homelessness based upon the original tool developed by Conover and Herman (2007) (31). De Vet's CTI fidelity scale captured (a) compliance fidelity (assessing the level to which staff are engaging with CTI elements) and (b) competence fidelity (assessing chart quality and completeness) (30). This tool includes 12 items, each of which comprises one to five criteria rated as "fulfilled" (score of 1 ) or "not fulfilled" (score of 0 ). Item-level fidelity ratings were obtained by dividing the number of positively rated criteria by the total number of criteria comprising each item. Fidelity ratings are interpreted on a five-point scale from "not implemented" to "ideally implemented". Table 1 outlines each item. 
Table 1

Overview of the de Vet et al. fidelity scale and underlying program attribute each item assesses

de Vet fidelity scale component

Item 1 (Three phases). Adherence to fixed duration for each of 3 phases, 3 months each phase ( \pm 2 weeks).

Item 2 (Nine month follow-up). Follow-up during nine month CTI program.
Program attribute being assessed

Duration of the program components. Each phase has a \pm 2 week grace.

Likelihood of providing client with nine-months of programming and saying in touch with them until the end.

Item 3 (Time limited). Recovery plan(s) completed with no more than nine months of intervention.

Whether the time-limited nature of CTI is feasible for clients.

Item 4 (Focused). Activities for each phase focus on no fewer than 1 and no more than 3 areas.

Item 5 (Early engagement). Engagement with client within 30 days of enrolment to begin relationship building.

Item 6 (Early Linking). Link client to services and network early, during Phase I.

Item 7 (Outreach). Case manager meets with client and connect them with diverse network and service partners early, with many meetings occurring in the community.

Item 8 (Monitoring). Client maintains regular contact with program staff continually through the program.

Item 9 (Intake Assessment). Case managers assess clients' risks, needs, and resources at the onset of the program.

Item 10 (Phase Planning). Phase plan(s) are completed with clients surrounding intended goals.

Item 11 (Progress Notes). Contacts and meetings between client and case managers, professionals or members of social network are documented throughout the program using specific notes.

Item 12 (Closing Note). Details pertaining to clients' experience and completion of the program, and future expectations are documented in closing note.
Applicability of focused activities for clients.

Whether 30 days are sufficient for client relationship building.

Whether clients can be linked to services in Phase 1 of the program.

Whether it is feasible for clients to meet with service partners in the community early on in the program.

Regular client engagement throughout the program.

The effectiveness of intake procedures to determine risks, needs, and resources of clients.

Phase plans as a guide to align planned interventions with clients' goals.

Role of phase notes in improving program success.

Role of closing notes in documenting client completion of program.

In order to determine the applicability of the fidelity tool taken from de Vet and colleagues (30), we shared the scale with EDH program staff and discussed potential areas of alignment (or lack thereof) with EDH given the different focus of the program. Program staff in an iterative fashion provided feedback, over 
multiple in person meeting sessions, while moving stepwise through the tool and determining its fit with the program theory, implementation, and its applicability to the program participants. Minor adaptations were made where necessary as described in the results section.

\section{Fidelity assessment}

The adapted scale was used to assess fidelity of EDH. Of the 17 women enrolled into the first year of the evaluation of the Item program, data from 8 women were included in the fidelity assessment. Written consent was provided from all participants prior to research staff accessing CTI notes. Participants engaged in the EDH program had to be 18 or older, be located in the Greater Toronto Area and have at least two of the following: (1) limited social support system, (2) experiencing or experienced conflict with the law, (3) experiences of negative effects as a result of substance use, (4) limited/ lack of employment skills or experience/ experiencing unemployment, (5) limited common life skills, (6) unsafe due to experiences of abuse, and (7) experiencing homelessness or housing precarity. The study was approved by St. Michael's Research Ethics Board (approval \#18-215).

Data to complete the fidelity assessment were extracted from women's CTI notes completed by their case manager. CTI notes were stored in an online platform for nonprofit organizations to securely manage client data, report to funders, and engage with clients via their computer or phone. To complete the assessment for fidelity items 1-4 and 10 (Three Phases, Nine Month Follow-up, Time Limited, Focused, and Phase Planning), participants' Phase Treatment Plans were reviewed to assess start and end dates of each CTI phase and determine compliance with the nine month time limit of CTI as well as identify CTI focus areas during each phase. CTI Progress Notes which document each meeting between case managers and clients as well as others in attendance were used to assess Items 5, 6, 7, 8 and 11 (Early Engagement, Early Linking, Outreach, Monitoring, Progress Notes). The Intake Form was also used for item 5 to ensure its completion within the first 6 weeks of Phase 1. The Assessment Form was used to assess item 9. The Closing Note completed at the end of the program was used to determine whether a transfer of care meeting was held and whether feedback on clients' CTI experience and progress through the program had been gathered.

Prior to undertaking the fidelity assessment, research staff (PB) attended a CTI training call with a CTI trainer from the Center for Urban Community Services to learn about the key principles of CTI. PB rated each criterion within the fidelity scale as "fulfilled" (score of 1 ) or "not fulfilled" (score of 0 ) for each participant and computed the mean score for each criterion across participants. To obtain fidelity ratings at the item level, we divided the number of criteria rated as "fulfilled" by the total number of criteria within that item and calculated a percentage of "fulfilled criteria". Percentages were interpreted as suggested in light of a five-point rating scale: item not implemented in line with the CTI model (percentage of fulfilled criteria $\leq 40 \%)$, poorly implemented (41\%-55\%), fairly implemented (56\%-70\%), well implemented $(71 \%-85 \%)$ and ideally implemented (percentage of fulfilled criteria $>85 \%)$. Scores for each criterion were entered into an Excel worksheet and fidelity ratings calculated. 


\section{Results}

\section{Fidelity Scale Adaptation}

Following discussions with the program staff, the following items of the de Vet (2017) (30) scale were adapted: Items $1,3,6,7,8,11$, and 12. According to the program staff items 1 and 3 , which surrounded the three phases and time limited nature of the CTI program, were not appropriate for the program participants and the time needed to build a rapport and needed to be lengthened. The 2-week margin on top of the strict 3 month window for each of the 3 phases of CTI were unrealistic for the contextual factors common to women who engage in such work such as their transient nature and likelihood of struggling with substance use and mental health disorders.(32) These factors were also hypothesized to influence the feasibility of women completing the program in a frame of 9 months.

According to the CTI model, early linkages with support networks (Item 6) should occur in Phase 1 of CTI. However, keeping in view the reality of the program's clientele, participants are often connected with some of their support resources such as the psychiatrist and housing worker in the pre-CTI phase instead of Phase 1. As a result of this, the program team recommended that progress notes from both pre-CTI and CTI be included while scoring this item.

There are unique differences between the CTI model and EDH's service delivery with respect to item 6 that were noted by the program staff. Primarily, while item 6 in the de Vet (30) scale allows the case managers to meet with their clients both at home and at locations where clients receive services, it is EDH's program policy to not meet with clients in their home (staff only meet with women either at the program's office location or in public places) to maximize safety. As outlined by the CTI model, item 6 assesses the involvement of women's formal and informal support networks. However, the program team clarified that many women's families do not know about their involvement in sex work. Item 6 also assesses meetings between people from the support networks without the client. However, the program purposefully avoids any meetings without the client, as keeping the client involved every step of the way, including when connecting with the client's care team, builds trust among the client with staff. As such, these criteria under item 6 were removed from our adapted fidelity scale. Item 6 in the adapted tool assesses whether: 1) during the first two weeks of Phase 1, case managers met with the client where they receive services and 2) during Phase 1 case managers met with the client and at least one member from their professional network.

'Outreach' (item 7) for the program team implied reaching out to women who were not yet involved with the program. This item was renamed 'Maintenance' which is more reflective of the areas covered such as holding progress meetings with CTI clients in the community, office or by phone. The program staff suggested to include texts and emails to the methods of scheduling meetings in addition to phone calls as some women preferred communicating that way. Program staff also noted many women preferred to meet in the office due to safety concerns, instead of in the community as outlined in the tool. For example, housing is an issue for many women who may be couch surfing and not renting a house. It was 
suggested to exclude the criterion of having at least one meeting with the person whom the client is renting their accommodation. Regarding meeting with the clients' family or informal support network, this is not realistic as most women's family members may not be aware of their involvement in sex work, they did not have family, or their family did not accept their involvement in sex work.

With respect to item 8 (Monitoring), the program team highlighted that the transient nature of the clients contributed to case managers periodically losing touch with women, which could cause delays in scheduling meetings. As outlined previously, developing trust and rapport with program participants requires time, which prompted the suggested adaptation of increasing the follow-up period between meetings from 21 days to 31 days. In relation to item 11 (progress notes), the program staff suggested to exclude the criterion of reconnecting relationships between clients and their social networks, as women's social network may not be aware of their involvement with sex work. Lastly, in regards to the de Vet et al (30) CTI fidelity scale, item 12 (closing notes) focused on transfer of care meetings between clients, case workers and a professional. However, not all women hold a transfer of care meeting at the end of the program, which led program staff to recommend removing the criterion of assessing transfer of care from the fidelity assessment. An overview of how each item was adapted can be seen in Table 2 . 
Table 2

Description of adapted fidelity scale

\begin{tabular}{|lll|}
$\begin{array}{l}\text { Item } \\
\text { number }\end{array}$ & Adaptation of fidelity scale item & Rationale for adaptation of fidelity scale item \\
\hline Item 1 & $\begin{array}{l}\text { CTI Phases were extended (i.e., CTI } \\
\text { phases lasted } 3 \text { months }+/-3 \text { to } 4 \\
\text { weeks. }\end{array}$ & $\begin{array}{l}\text { Each CTI phase was extended to }+/-3-4 \text { week } \\
\text { periods instead of the } 2 \text { weeks suggested by the } \\
\text { de Vet tool, as it was not appropriate for this } \\
\text { population. The transient nature of this } \\
\text { population, mobility issues to make } \\
\text { appointments with case managers, mental } \\
\text { health and addiction issues and the need for } \\
\text { staff to build trust with women all called for a } \\
\text { larger time period of CTI phases. }\end{array}$ \\
\hline
\end{tabular}

Item 2 Not adapted

Item 3 Time limited nature of the program was extended

The de Vet fidelity scale measured how well the program maintained its strict 9 month timeline for CTI. As this was not feasible, as outlined in item 1, item 3 was adapted to allow an extension of 3-4 weeks to the 9 month CTI instead of 2 weeks.

Item $4 \quad$ Not adapted

Item $5 \quad$ Not adapted

Item $6 \quad$ Staff did not meet clients in their homes, did not contact family or friends and did not meet support networks and resources without clients present.

An intentional decision was made for staff not to meet clients in their homes to protect the safety of staff as some women may be living with violent partners. Staff may meet with clients in the lobby of their apartment buildings, but not within their homes.

Further, due to the occult nature of sex work, many women's network members may not know they are involved with sex work and prefer to keep this unknown from friends and family. Similarly, at the core of the program is the goal to work alongside women and thus meeting with anyone to discuss clients without the client present goes against the intention of the program.

Item $7 \quad$ "Outreach" was renamed

"Maintenance" and included maintaining ongoing contact with clients through varying forms of communication including text messages. Moreover, sub-items related to meeting with housemates and landlord as well as having 3 calls with a residential caregiver or housemate were removed.
The points under this item did not capture what the program team does in terms of outreach. Outreach for the program team occurs before women enroll into the program. Activities listed under item 7 refer to activities occurring in phase 1 of CTI.

As the de Vet fidelity tool focused on those seeking housing, criteria related to meeting with landlords, housemates and residential caregivers were removed as housing, while a key element for women to successfully exit sex work, is not the sole focus of the program. 


\begin{tabular}{|c|c|c|}
\hline $\begin{array}{l}\text { Item } \\
\text { number }\end{array}$ & Adaptation of fidelity scale item & Rationale for adaptation of fidelity scale item \\
\hline Item 8 & $\begin{array}{l}\text { The window of time between meetings } \\
\text { during Monitoring (occurring during } \\
\text { Phase } 3 \text { ) was extended from } 21 \text { days } \\
\text { to } 31 \text { days. }\end{array}$ & $\begin{array}{l}\text { Time in-between meetings was extended to } 31 \\
\text { days in order to account for the transient nature } \\
\text { of this population as well as complex issues } \\
\text { clients may be dealing with. }\end{array}$ \\
\hline Item 9 & Not adapted & \\
\hline Item 10 & Not adapted & \\
\hline Item 11 & $\begin{array}{l}\text { Progress notes: the criterion for clients } \\
\text { having to reconnect relationships with } \\
\text { networks was removed. }\end{array}$ & $\begin{array}{l}\text { In line with item } 6 \text {, as women's social network } \\
\text { may not be aware of their involvement in sex } \\
\text { work, reconnecting with their social network is } \\
\text { not necessarily part of women's goals and } \\
\text { needs to make progress through the program. }\end{array}$ \\
\hline Item 12 & $\begin{array}{l}\text { Closing note: criterion pertaining to } \\
\text { holding transfer of care meetings was } \\
\text { removed. }\end{array}$ & $\begin{array}{l}\text { Some women ask not to have a transfer of care } \\
\text { meeting. Out of respect to client's wishes these } \\
\text { meetings are not held for all women. }\end{array}$ \\
\hline
\end{tabular}

\section{Fidelity Assessment}

Table 3 presents the implementation score for each item of the adapted scale. Half of the items (items 2 , $4,5,9,10$ and 11 ) were ideally implemented with a score of $>85 \%$. Of the remaining items, item 7 was scored as well implemented (score of $71 \%-85 \%$ ), item 12 was deemed fairly implemented (score of $56 \%-70 \%$ ) and items 6 and 8 were found to be poorly implemented (score of $41 \%-55 \%$ ). Finally, items 1 and 3 were ranked as $\leq 40 \%$, demonstrating the limited ability of implementing the program with strict timeliness as required both by CTI phases and time limits. 
Table 3

Exit Door Here implementation score for fidelity items

\begin{tabular}{|ll|}
\hline Implementation score & Adapted fidelity tool \\
\hline Ideally Implemented & Items $2,4,5,9,10$ and 11 \\
\hline $85 \%$ & \\
Well Implemented & Item 7 \\
$71 \%-85 \%$ & \\
\hline $\begin{array}{l}\text { Fairly Implemented } \\
56 \%-70 \%\end{array}$ & Item 12 \\
\hline $\begin{array}{l}\text { Poorly Implemented } \\
41 \%-55 \%\end{array}$ & Items 6 and 8 \\
\hline $\begin{array}{l}\text { Not Implemented } \\
\leq 40 \%\end{array}$ & Items 1 and 3 \\
\hline
\end{tabular}

\section{Discussion}

Contextual factors, which are relevant for women who engage in sex work such as prevalence of substance use, safety concerns, or criminalization, contribute to their unique needs in relation to health and social programs. This fidelity assessment of the program presents one of the first adaptations and evaluations of a CTI programmatic model for women who engage in sex work. Through refining and applying the fidelity assessment tool, we were able to determine that selected components of the original CTI model were not entirely appropriate, and therefore required adaptation to effectively reflect the needs and reality of this target population.

We found that the EDH program was implemented with 'ideal' fidelity for half the items assessed. The two items which were poorly implemented $(6 \& 8)$ speak to challenges that the program staff had in completing the early linking process to program staff and exterior services, as well as monitoring program participants through the process. This can be attributed to contextual factors (e.g., substance use, mental health issues, housing instability) relevant for women who engage in sex work and the challenges these bring in maintaining a stringent time-sensitive program (32).

Discussions surrounding what factors of the original CTI fidelity assessment tool must be adapted to effectively meet the needs of diverse groups of individuals has been constant throughout the literature $(31,33,34)$. Herman and colleagues propose a set of questions surrounding if, and how, the original CTI fidelity tool should be adapted to include factors such as whether the nine month time-line is realistic, if factors that impact the effectiveness of CTI vary between populations, and what adaptations are needed to ensure CTI is effective for diverse cultural and ethnic groups (31). 
The necessary adaptations made to the CTI fidelity assessment tool for this study demonstrates the importance of considering context when developing, implementing, and evaluating health and social programs. Factors unique to the populations of interest such as their transient nature, unique gendered needs, or experiences with past trauma, influence how they will interact with programs and what they need from them. Factors pertaining to the programs themselves and the context within which they are deployed, including characteristics of staff who are implementing the program and availability and accessibility of services, also influence the implementation and effectiveness of these programs (34). Acknowledging the role context plays in the implementation and effectiveness of programs brings to light the tensions between theory and practice. For example, we can see how theoretically the three month per stage time period indicated by the original CTI is recommended for ensuring the transition process was rapid. However, given the complexity of addressing multiple priorities (e.g., housing, employment, personal health) and with the specific systems barriers faced by the participants in the EDH program (e.g., very little affordable housing) program staff realized the 3 month duration for each phase was not reasonable for our target population. In addition the complex, multi-layered issues of housing, mental health and addiction issues, with some also have mobility challenges, keeping and attending meetings with caseworkers and community connections are difficult. Further, women's progress to exiting is not linear, with setbacks along the way making more time during CTI phases necessary. Thus, lengthening the duration of each Phase is an important adaptation of the program and the fidelity tool.

Herman and Mandiberg (35) describe how original CTI models have been adapted to various populations beyond the model's original focus on individuals experiencing homelessness transitioning to stable housing. This has included individuals who experience mental health illnesses, individuals exiting the criminal justice system, homeless mothers with children, and women who have experienced domestic violence. Other scholars have also documented that common areas of the model which have had to be adapted include its time-sensitive nature $(23,25,30,36)$. Therefore we can see that although our study focuses on women who engage with and are attempting to exit sex work, the adaptations made to the original CTI model are consistent with other populations.

Our study has several strengths. Primarily is the fact that this study represents the first to conduct a fidelity assessment of an evidence-based intervention on sex work. As such, it contributes to the current understanding of how CTI models can be used among women who engage with or are attempting to exit sex work. Beyond this, it can help individuals understand what type and features of programming may work better (or not work) with this population. For example, one could try to implement a very time limited, strict program that is not CTI, and this, in light of our findings, might not work that well. An additional strength includes the use of both quantitative and qualitative methods in the assessment of program fidelity and CTI tool adaptation. Despite these strengths, this study also holds limitations. The sample of participants included in this study were from one program located in an urban centre (Toronto, Ontario). Due to this, particular sub-populations among women-identifying individuals who engage in sex work in other regions may have yielded different results (i.e., differing contexts within smaller regions or with higher resources). Identifying the strengths and limitations of using a CTI model in programs aimed at assisting women-identifying individuals exit sex work can assist in improving current programs and 
services that exist for this sector. These improvements will not only improve these populations' current access to essential services, but may also assist many in completing the transition out of sex work. The integrated nature of the CTI model may also allow for continuity of care in many areas of need for these groups in areas such as housing, mental health and addiction. When implementing future CTI models within programs geared towards assisting women-identifying individuals exit sex work, it is essential that these contextual circumstances are considered.

\section{Conclusion}

Overall, this study has highlighted considerations for future CTI programs, which aim measure program fidelity in providing care to women who engage with sex work. Our findings reiterate the importance of context in not only conducting fidelity assessments but in designing and implementing fidelity tools for varying groups. Future research is needed to determine what the most effective program model is in assisting women exit sex work and maintain overall health and well-being.

\section{Declarations}

\section{Ethics approval and consent to participate}

All participants consented to participating in this study. The study was approved by St. Michael's Research Ethics Board (approval \#18-215).

\section{Consent for publication}

All participants consented to participating in this study.

\section{Availability of data and materials}

NA

\section{Competing interests}

The authors have no competing interests to declare.

\section{Funding}

This project was funded by Public Safety Canada following a call for developing, implementing and evaluating sex work-exiting programs in Canada. MS is supported by a Tier 2 Canada Research Chair in Urban Health Equity Among Young People (2020-2025).

\section{Authors' contributions}

MP wrote the original draft of the manuscript, aided in manuscript content conceptualization, completed revisions, and helped manage the development of the manuscript. 
MS conceptualized the paper and contributed to reviewing all drafts of the manuscript.

PB contributed to data collection and analysis, writing and reviewing all drafts of the manuscript.

$\mathrm{MH}$ contributed to data collection and analysis, writing and reviewing all drafts of the manuscript.

PO contributed to conceptualizing the paper, reviewing all drafts of the manuscript, and provided supervision and guidance for the manuscript.

All authors approved of the final version of the manuscript.

\section{Acknowledgements}

We would like to acknowledge the program team, women who are enrolled in the program

\section{References}

1. Fisher R, Smith K, Finney S, Pinder K. The Importance of Implementation Fidelity Data for Evaluating Program Effectiveness. About Campus. 2014 Nov 1;19(5):28-32.

2. Dobson D, Cook TJ. Avoiding type III error in program evaluation. Results from a field experiment. Eval Program Plann. 1980 Jan 1;3(4):269-76.

3. Breitenstein SM, Gross D, Garvey CA, Hill C, Fogg L, Resnick B. Implementation fidelity in communitybased interventions. Res Nurs Heal. 2010 Apr;33(2):164-73.

4. Fernandez ME, Liang S, Jacobs SR, Taplin SH, Weiner BJ. Pressing ahead: developing and testing of new measures in implementation science. Implement Sci. 2015 Dec;10(S1):A14.

5. The Runner | Explainer: The Legality of Sex Work in Canada During COVID-19 [Internet]. [cited 2021 May 31]. Available from: https://runnermag.ca/2020/07/explainer-the-legality-of-sex-work-in-canadaduring-covid-19/

6. Prostitution offences in Canada: Statistical trends [Internet]. [cited 2021 May 20]. Available from: https://www150.statcan.gc.ca/n1/pub/85-002-x/2016001/article/14670-eng.htm

7. Sex trafficking still a prevalent issue across Canada, advocates and police say | CTV News [Internet]. [cited 2021 May 20]. Available from: https://www.ctvnews.ca/canada/sex-trafficking-still-a-prevalentissue-across-canada-advocates-and-police-say-1.4820944

8. Reid LA. Improving the Quality of Life for Street Level Sex Workers: A Case Study of their Experiences with Stigma in the Downtown Eastside [Internet]. 2007 [cited 2021 May 27]. Available from: http://ir.lib.sfu.ca/handle/1892/112

9. Overall C. Project MUSE - Sex Work: For Whom? By Whom? J Can Stud. 2016;50(1):252-61.

10. Hankel J, Dewey S, Martinez N. Women exiting street-based sex work: Correlations between ethnoracial identity, number of children, and violent experiences. J Evidence-Informed Soc Work. 2016;13(4):412-24. 
11. Hodzic S, Chrismas R. Taking back the power: The link between poverty and Canada's sex industry. J Community Saf Well-Being. 2018 Oct 17;3(2):34.

12. Williamson C, Folaron G. Understanding the Experiences of Street Level Prostitutes. Qual Soc Work. 2003 Aug 15;2(3):271-87.

13. Cimino AN. Sex work and adult prostitution: From entry to exit. In: Handbook of Behavioral Criminology. Springer International Publishing; 2018. p. 239-55.

14. Vanwesenbeeck I. Sex Work Criminalization Is Barking Up the Wrong Tree. Arch Sex Behav [Internet]. 2017 Aug 1 [cited 2021 May 20];46(6):1631-40. Available from: https://link.springer.com/article/10.1007/s10508-017-1008-3

15. Platt L, Grenfell P, Meiksin R, Elmes J, Sherman SG, Sanders T, et al. Associations between sex work laws and sex workers' health: A systematic review and meta-analysis of quantitative and qualitative studies. PLoS Med. 2018;15(12):e1002680.

16. Dalla RL. "You can't hustle all your life": An exploratory investigation of the exit process among street-level prostituted women. Psychol Women Q. 2006;30(3):276-90.

17. Koegler E, Preble KM, Cimino AN, Stevens JE, Diehl S. Examining Recidivism in a Prostitution Diversion Program. Int J Offender Ther Comp Criminol. 2020 Feb 1;64(2-3):232-48.

18. Bowen EA, Canfield JP, Trostle A, Harley D. Predictors of stable housing for homeless women leaving a sex work-exiting program. Fam Soc. 2015 May 3;96(4):268-76.

19. Bowen RR. Squaring Up: Experiences of Transition from Off-Street Sex Work to Square Work and Duality-Concurrent Involvement in Both-in Vancouver, BC. Can Rev Sociol. 2015 Nov 1;52(4):429-49.

20. Hickle KE, Roe-Sepowitz D, Rankin L, Sabella WD. Getting out: A Qualitative Exploration of the Exiting Experience Among Former Sex Workers and Adult Sex Trafficking Victims. 2014.

21. Shareck M, Buhariwala P, Hassan M, O'Campo P. Helping women transition out of sex work: Study protocol of a mixed-methods process and outcome evaluation of a sex work exiting program. BMC Womens Health. 2020 Oct 9;20(1).

22. Critical Time Intervention | CTI Model | Critical Time Intervention [Internet]. [cited 2021 May 20]. Available from: https://www.criticaltime.org/cti-model/

23. Lennox C, Stevenson C, Edge D, Hopkins G, Thornicroft G, Susser E, et al. Critical Time Intervention: a qualitative study of the perspectives of prisoners and staff. J Forensic Psychiatry Psychol. 2020 Jan 2;31(1):76-89.

24. Nossel IR, Lee RJ, Isaacs A, Herman DB, Marcus SM, Essock SM. Use of peer staff in a critical time intervention for frequent users of a psychiatric emergency room. Psychiatr Serv. 2016 May 1;67(5):479-81.

25. Lako DAM, Beijersbergen MD, Jonker IE, de Vet R, Herman DB, van Hemert AM, et al. The effectiveness of critical time intervention for abused women leaving women's shelters: a randomized controlled trial. Int J Public Health. 2018;63(4):513-23. 
26. Millen AM, Levinson A, Linkovski O, Shuer L, Thaler T, Nick GA, et al. Pilot study evaluating critical time intervention for individuals with hoarding disorder at risk for eviction. Psychiatr Serv. $2020 \mathrm{Apr}$ 1;71(4):405-8.

27. Herman DB, Conover S, Gorroochurn P, Hinterland K, Hoepner L, Susser ES. Randomized trial of critical time intervention to prevent homelessness after hospital discharge. Psychiatr Serv. 2011;62(7):713-9.

28. Hanesworth, C., \& Herman D. Homelessness Prevention and Intervention in Social Work. Homelessness Prevention and Intervention in Social Work. Springer International Publishing; 2019.

29. Barrenger SL, Kriegel LS, Angell B, Draine J. Role of context, resources, and target population in the fidelity of critical time intervention. Psychiatr Serv. 2016 Jan 1;67(1):115-8.

30. de Vet R, Lako DAM, Beijersbergen MD, van den Dries L, Conover S, van Hemert AM, et al. Critical Time Intervention for People Leaving Shelters in the Netherlands: Assessing Fidelity and Exploring Facilitators and Barriers. Adm Policy Ment Heal Ment Heal Serv Res. 2017;44(1):67-80.

31. Herman D, Conover S, Felix A, Nakagawa A, Mills D. Critical time intervention: An empirically supported model for preventing homelessness in high risk groups. J Prim Prev. 2007 Aug;28(34):295-312.

32. Ward H, Day S. What happens to women who sell sex? Report of a unique occupational cohort. Sex Transm Infect. 2006 Oct;82(5):413-7.

33. Samuels J, Fowler PJ, Ault-Brutus A, Tang DI, Marcal K. Time-limited case management for homeless mothers with mental health problems: Effects on maternal mental health. J Soc Social Work Res. 2015 Dec 1;6(4):515-39.

34. Chen F-P. Exploring How Service Setting Factors Influence Practice of Critical Time Intervention. J Soc Social Work Res. 2012;3(1):51-64.

35. Herman DB, Mandiberg JM. Critical time intervention: Model description and implications for the significance of timing in social work interventions. Res Soc Work Pract. 2010;20(5):502-8.

36. Shinn M, Samuels J, Fischer SN, Thompkins A, Fowler PJ. Longitudinal Impact of a Family Critical Time Intervention on Children in High-Risk Families Experiencing Homelessness: A Randomized Trial. Am J Community Psychol. 2015 Aug 4;56(3-4):205-16.

\section{Supplementary Files}

This is a list of supplementary files associated with this preprint. Click to download.

- StaRIChecklistCTI.docx 